\title{
Teratogenic Activity of 2-Amino-1,3,4-thiadiazole Hydrochloride in Wistar Rats and the Protection Afforded by Nicotinamide ${ }^{1}$
}

ALLAN R. BEAUDOIN

Department of Anatomy, University of Michigan, Ann Arbor, Michigan 48104

\begin{abstract}
Pregnant Wistar rats were each injected once ip with various doses of 2-amino-1,3,4-thiadiazole hydrochloride (ATDA) at days 1-16 of gestation (sperm day $=$ day 0 ). The optimal teratogenic dose was determined to be $100 \mathrm{mg} / \mathrm{kg}$ and this dose was employed throughout the experiment. At autopsy at day 20 resorptions and malformations were found in all litters from treated females. Two periods of increased embryonic susceptibility to the lethal effects of ATDA were observed. The first at day 5 (100\% resorbed) and the second at days 9 and 10 ( 71.5 and $92.5 \%$ resorbed). Periods of increased sensitivity to the teratogenic action of ATDA were at days 9 through 13, when the incidence of abnormal fetuses produced exceeded $90 \%$. The major malformations were anophthalmia, microphthalmia, hydrocephalus, short tail, taillessness, ectrodactyly, syndactyly, and cleft palate. Other malformations occurred occasionally. The malformations were related to the developmental stage at the time of treatment. Supplemental treatment with nicotinamide at days $5,11,12$, and 13 markedly diminished the teratogenic and lethal effects of ATDA, and at day 11 the administration of nicotinamide completely abolished its teratogenic activity. ATDA probably acts by interfering with NAD-dependent enzyme reactions.
\end{abstract}

The first report of teratogenic action for a 2-substituted thiadiazole (fig. 1) was made by Murphy et al. ('57). They injected 2-ethylamino-1,3,4-thiadiazole into rats on gestation day 9,11 , or 12 (sperm day = day 0 ), but only day-11 treatment produced gross abnormalities, largely confined to the axial skeleton. Little else appears to have been done with respect to the teratogenic action of the 2-substituted thiadiazoles until the reports by Beaudoin (72) and Scott et al. ('72). The latter demonstrated a depression in DNA synthesis in embryos from females treated with aminothiadiazole.

The thiadiazoles have been reported to have carcinostatic activity against mouse tumors (Oleson et al., '55) and a uricogenic effect in man (Krakoff and Magill, '56). Nicotinamide has been used to protect against the antitumor and toxic effect of thiadiazole in mice (Shapiro et al., '57; Humphreys et al., '62) and to protect against the uricogenic effect in human beings (Krakoff and Balis, '59). Recently nicotamide was reported to abolish the teratogenic action of thiadiazole in rats (Beaudoin, '72; Scott et al., '72).
The present investigation was undertaken to explore the teratogenic action of 2-amino-1,3,4-thiadiazole over a considerable portion of the gestation period in rats and to investigate the ability of nicotinamide to protect against this action.

\section{MATERIALS AND METHODS}

Virgin female Wistar rats from our colony were used. The animals were maintained on a Rockland Complete Rat Diet ad libitum, with supplemental feedings of lettuce. Day 0 of pregnancy was considered to begin on the morning sperm were found in the vaginal smear.

2-Amino-1,3,4-thiadiazole hydrochloride (ATDA) (Eastman Kodak, Rochester), usually as a $2 \%$ aqueous solution, was administered ip, $100 \mathrm{mg} / \mathrm{kg}$ maternal body weight. In a few experiments various doses were used to determine the optimal teratogenic dose; these will be noted below. Nicotinamide (Sigma) was prepared so that the single dose to be injected was contained in $1 \mathrm{ml}$ of solution. The effect of

Received July 24,'72. Accepted Oct. 9, '72.

1 Supported by NIH grant HDO0400. 

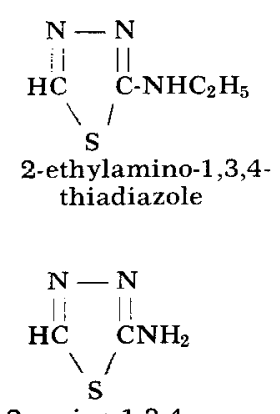

2-amino-1,3,4thiadiazole

Fig. 1 Structural formulae of 2-amino-1,3,4thiadiazole and 2-ethylamino-1,3,4-thiadiazole.

ATDA on pregnancy was tested at days 1-16 of gestation. The effect of nicotinamide on the teratogenic and embryocidal action of ATDA was investigated at days $5,11,12,13$, and 15 .

Pregnancy was terminated at day 20, resorption sites were counted, and the fetuses were recovered, weighed, and fixed. Those fixed in Bouin's fluid were freehand sectioned with a razor blade and each slice was examined for malformations. Fetuses fixed in $95 \%$ alcohol were prepared for staining with alizarin red $S$ for visualization of the skeleton. Placentae were also recovered and weighed.

\section{RESULTS}

The optimal teratogenic dose of ATDA was determined by injecting females with various concentrations of the drug at day 11 of gestation (table 1). Day 11 was selected because Murphy et al. ('57) reported gross malformations in surviving fetuses of females treated at this time. A 2\% solution of ATDA was used for the 200 and $100 \mathrm{mg} / \mathrm{kg}$ doses, $0.5 \%$ solution for 50 and $25 \mathrm{mg} / \mathrm{kg}$, and $0.2 \%$ solution for 10 and $5 \mathrm{mg} / \mathrm{kg}$. The ATDA solution strength was varied to keep the injection volume in the same range for all dosages (i.e., 1-2 $\mathrm{ml}$ per animal). Table 1 shows that $100 \mathrm{mg} / \mathrm{kg}$ was markedly teratogenic, only nine implantation sites of 270 being normal, and those all in the same litter (table 2). No attempt was made to determine the minimum teratogenic dose.

The pregnant females tolerated the injection quite well at all stages of gestation except at day 7 and 16 (44 and 33\% maternal deaths, respectively). A total of 172 pregnant rats were injected. All of the 33 females that died gave evidence of vaginal bleeding 48-96 hours postinjection. Death occurred from 2-11 days following injection, but $80.3 \%$ of them occurred by 48-96 hours of treatment. The necropsy report from our Unit for Laboratory Animal Medicine listed the cause of death in these animals as acute peritonitis. The $p \mathrm{H}$ of the ADTA solution was found to be 2.15, sufficiently acid to have caused local necrosis of the bowel with a resultant peritonitis.

Table 2 gives the results of injecting a teratogenic dose of ATDA on single days over much of the gestation period. Two times during embryonic development were noted to be particularly susceptible to the embryocidal effects of ATDA treatment: the first at gestation day 5 and the second days 9 and 10. Six of the eight rats surviving treatment at day 5 presented no indication of implantation at the time of autopsy. All six had positive sperm smears and, furthermore, three of them had been mated on the same day but with three different males. It is unlikely, although possible, that all were nonpregnant. In

TABLE 1

Results of experiments to determine the optimal teratogenic dose of 2-amino-1,3,4-thiadiazole at gestation day 11 in Wistar rats

\begin{tabular}{ccccc}
\hline $\begin{array}{c}\text { Dosage } \\
(\mathrm{mg} / \mathrm{kg})\end{array}$ & $\begin{array}{c}\text { Number females } \\
\text { injected/ } \\
\text { surviving }\end{array}$ & $\begin{array}{c}\text { Total no. } \\
\text { implantation } \\
\text { sites }\end{array}$ & $\begin{array}{c}\text { \% implantation } \\
\text { sites resorbed } \\
\text { or dead }\end{array}$ & $\begin{array}{c}\text { \% survivors } \\
\text { malformed }\end{array}$ \\
\hline 200 & $6 / 0$ & - & - & - \\
100 & $24 / 24$ & 270 & 37.5 & 94.6 \\
50 & $6 / 5$ & 69 & 10.2 & 29.1 \\
25 & $6 / 6$ & 75 & 1.3 & 20.3 \\
10 & $6 / 6$ & 69 & 2.9 & 4.0 \\
5 & $6 / 6$ & 74 & 5.4 & 4.1 \\
\hline
\end{tabular}


TABLE 2

Results of ip injection of $100 \mathrm{mg} / \mathrm{kg}$ 2-amino-1,3,4-thiadiazole $\mathrm{HCl}$ during pregnancy in Wistar rats

\begin{tabular}{|c|c|c|c|c|c|}
\hline $\begin{array}{l}\text { Day of } \\
\text { treatment }\end{array}$ & $\begin{array}{l}\text { Number females } \\
\text { injected/ } \\
\text { surviving }\end{array}$ & $\begin{array}{c}\text { Total } \\
\text { implant. } \\
\text { sites }\end{array}$ & $\begin{array}{c}\% \\
\text { resorbed }\end{array}$ & $\begin{array}{c}\% \\
\text { survivors } \\
\text { malformed }\end{array}$ & $\begin{array}{c}\text { Fetal } \\
\text { weight }(g)\end{array}$ \\
\hline & & & & & mean $\pm S D$ \\
\hline 1,2 , or 3 & $10 / 10$ & 123 & 8.2 & 23.9 & $3.63 \pm 0.37$ \\
\hline 4 & $7 / 5$ & 59 & 40.7 & 25.6 & $2.98 \pm 0.40$ \\
\hline 5 & $11 / 8$ & 241 & 100.0 & - & - \\
\hline 6 & $13 / 10$ & 105 & 22.8 & 33.2 & $3.30 \pm 0.60$ \\
\hline 7 & $16 / 9$ & 107 & 28.9 & 25.0 & $3.45 \pm 0.26$ \\
\hline 8 & $12 / 9$ & 110 & 25.4 & 28.1 & $3.70 \pm 0.37$ \\
\hline 9 & $13 / 10$ & 105 & 71.5 & 83.5 & $2.73 \pm 0.21$ \\
\hline 10 & $17 / 14$ & 158 & 92.5 & 100.0 & - \\
\hline 11 & $25 / 24$ & 270 & 37.5 & $94.6^{2}$ & $2.54 \pm 0.65$ \\
\hline 12 & $10 / 8$ & 110 & 10.0 & 98.0 & $2.62 \pm 0.61$ \\
\hline 13 & $10 / 8$ & 101 & 21.8 & 98.7 & $2.53 \pm 0.65$ \\
\hline 14 & $12 / 11$ & 133 & 15.1 & 62.0 & $3.26 \pm 0.55$ \\
\hline 15 & $10 / 10$ & 116 & 4.9 & 9.0 & $2.93 \pm 0.30$ \\
\hline 16 & $9 / 29$ & 86 & 12.8 & 5.3 & $2.94 \pm 0.66$ \\
\hline \multicolumn{6}{|l|}{ Untreated } \\
\hline controls & $29 / 29$ & 370 & 2.7 & 0.58 & $3.84 \pm 0.47$ \\
\hline
\end{tabular}

1 Implantation occurred in only two females.

2 Only 9 fetuses were normal and they were all in the same litter.

addition each female exhibited evidence of vaginal bleeding during the 48 hours immediately following injection. Taken together these observations suggest an interference with implantation. Autopsy of the remaining two females treated at day 5 disclosed completely resorbed litters. The second critical time was at days 9 and 10 , at which times 71.5 and $92.5 \%$ respectively of the implantation sites were caused to be resorbed. Treatment at no other day in pregnancy produced over $40 \%$ resorption, days 5,9 , and 10 being different in this respect. The reason for this increased embryocidal action of ATDA is not known.

Embryonic susceptibility to the teratogenic action of ATDA varied throughout pregnancy. The most susceptible period was days 9-13. Table 3 lists the relative frequency of the major malformations seen following ATDA treatment. The days of treatment have been grouped to emphasize differences in resorption rates and in the appearance of specific malformations. The table-heading "other" includes too many different abnormalities to list individually. They were infrequent except for hydronephrosis. Because of the report of Woo and Hoar ('72) hydronephrosis was not included as a frequent malformation. Further work is necessary to differentiate between apparent hydronephrosis and true hydronephrosis in the day-20 rat fetus. ATDA produced high incidence of absent or malformed tail following maternal treatment at days 10-12 and of digital defect after treatment at days 11-14. The finding of tail malformations after treatment at days $1-4$ is open to question since the defect consisted of crooked or hooked tails only, certainly a minor malformation at best, and no skeletal abnormalities were seen in the tails of these animals. However, treatment at days 10-12 resulted in short or stub tails in over $90 \%$ of the fetuses with tail defects. The distribution of other frequent anomalies was logical, viz., central nervous system malformations followed treatment early in gestation and skeletal abnormalities after treatment later in gestation.

Analysis of the skeleton revealed, in addition to elements affected by taillessness and ectrodactyly, abnormalities in the time of appearance of ossification centers (especially of the paws) and abnormalities of ribs and vertebrae. In general, treatment at days 6-9 resulted in fused or missing ribs; at days $10-11$ in short ribs and fusions between ossification centers in adjacent vertebrae, especially sacral; and at days 12-15 in absence of one or more ossification centers in the paws. Since we did not stain cartilage it is not possible to evaluate critically the appearance of the 


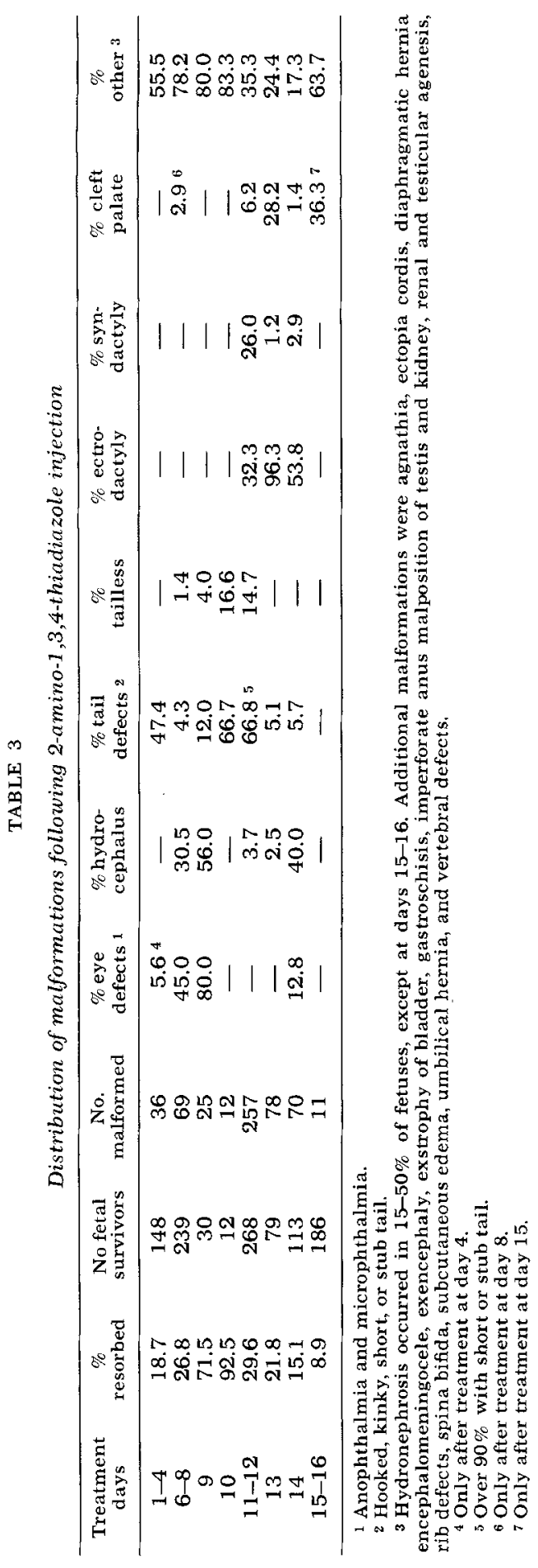

appendicular skeleton, however there appeared to be no fusion of the skeletal elements in syndactylous fetuses.

ATDA treatment usually resulted in significantly lighter fetuses at day 20 than were found in control litters owing to generalized growth retardation. Treatment at days $9-13$ produced the greatest reduction in fetal and placental weight. The mean weight $( \pm$ SD) of 370 control fetuses was $3.84 \pm 0.47 \mathrm{~g}$; that of fetuses exposed to treatment at days $9-13$ (444 fetuses) was $2.60 \pm 0.53 \mathrm{~g}(P<0.001)$. The corresponding placental weights were: control $0.53 \pm 0.15 \mathrm{~g}$ and experimental $0.22 \pm$ $0.04 \mathrm{~g}(P<0.001)$.

Table 4 contains data regarding the protective action of nicotinamide given in conjunction with ATDA at several times during gestation. Nicotinamide reduced the number of resorbed implantation sites when given at days 5,11 , and 13 but apparently had no such effect at days 12 and 15. Much more dramatic was the protection nicotinamide had against the teratogenic action of ATDA at the most susceptible period, days $11-13$. It is noteworthy that at day 11 the protection was absolute. Nicotinamide also protected fetuses against the growth retarding effect of ATDA. The mean weight $( \pm S D)$ of all fetuses (table 4) treated with ADTA plus nicotinamide was $3.85 \pm 0.42 \mathrm{~g}$, that for control fetuses was $3.84 \pm 0.47 \mathrm{~g}$, and for fetuses from females treated with ATDA only was $2.65 \pm 0.56$ g. Placental weights were similarly higher after the combined treatment than after ATDA. alone.

\section{DISCUSSION}

The optimal teratogenic dose of ATDA at day 11 was $100 \mathrm{mg} / \mathrm{kg}$, as was also found by Scott et al. (72). Day 11 was selected for determining the optimum teratogenic dose because many gross malformations had been produced by treatment at that time (Murphy et al., '57). But other days may yield still higher incidences of malformations than those reported here with larger doses of ATDA.

ATDA treatment during early organogenesis (days 6-9) resulted in a preponderance of fetuses with eye and central 
TABLE 4

Results of ip injection of $100 \mathrm{mg} / \mathrm{kg}$ 2-amino-1,3,4-thiadiazole (ATDA) plus $50 \mathrm{mg}$ nicotinamide (N)

\begin{tabular}{|c|c|c|c|c|c|c|c|}
\hline \multirow{2}{*}{ Day } & \multirow[b]{2}{*}{ Treatment } & \multirow{2}{*}{$\begin{array}{l}\text { Number } \\
\text { females } \\
\text { injected }\end{array}$} & \multirow{2}{*}{$\begin{array}{l}\text { Implant. } \\
\text { sites }\end{array}$} & \multirow{2}{*}{$\begin{array}{c}\% \\
\text { resorbed }\end{array}$} & \multirow{2}{*}{$\begin{array}{c}\% \\
\text { survivors } \\
\text { malformed }\end{array}$} & \multicolumn{2}{|c|}{ Weight (g) } \\
\hline & & & & & & Fetal & Placental \\
\hline 5 & $\begin{array}{l}\text { ATDA } \\
\text { ATDA }+\mathrm{N}\end{array}$ & $\begin{array}{l}8 \\
7\end{array}$ & $\begin{array}{l}24 \\
87\end{array}$ & $\begin{array}{r}100.0 \\
10.3\end{array}$ & $\overline{5.1}$ & $\begin{array}{r}\text { mear } \\
3.89 \pm 0.27\end{array}$ & $\begin{array}{l} \pm S D \\
0.47 \pm 0.04\end{array}$ \\
\hline 11 & $\begin{array}{l}\text { ATDA } \\
\text { ATDA }+\mathrm{N}\end{array}$ & $\begin{array}{r}24 \\
9\end{array}$ & $\begin{array}{l}270 \\
122\end{array}$ & $\begin{array}{r}37.5 \\
6.5\end{array}$ & $\begin{array}{c}94.6 \\
0.0\end{array}$ & $\begin{array}{l}2.54 \pm 0.65 \\
4.12 \pm 0.65\end{array}$ & $\begin{array}{l}0.22 \pm 0.05 \\
0.45 \pm 0.04\end{array}$ \\
\hline 12 & $\begin{array}{l}\text { ATDA } \\
\text { ATDA }+\mathbf{N}\end{array}$ & $\begin{array}{l}8 \\
6\end{array}$ & $\begin{array}{r}110 \\
82\end{array}$ & $\begin{array}{l}10.0 \\
15.8\end{array}$ & $\begin{array}{l}98.0 \\
11.7\end{array}$ & $\begin{array}{l}2.62 \pm 0.61 \\
3.75 \pm 0.53\end{array}$ & $\begin{array}{l}0.20 \pm 0.03 \\
0.35 \pm 0.06\end{array}$ \\
\hline 13 & $\begin{array}{l}\text { ATDA } \\
\text { ATDA }+\mathbf{N}\end{array}$ & $\begin{array}{l}8 \\
6\end{array}$ & $\begin{array}{r}101 \\
84\end{array}$ & $\begin{array}{r}21.8 \\
9.5\end{array}$ & $\begin{array}{r}98.7 \\
7.9\end{array}$ & $\begin{array}{l}2.53 \pm 0.65 \\
3.77 \pm 0.15\end{array}$ & $\begin{array}{l}0.23 \pm 0.06 \\
0.37 \pm 0.01\end{array}$ \\
\hline 15 & $\begin{array}{l}\text { ATDA } \\
\text { ADTA }+\mathbf{N}\end{array}$ & $\begin{array}{r}10 \\
6\end{array}$ & $\begin{array}{r}116 \\
75\end{array}$ & $\begin{array}{l}4.9 \\
2.7\end{array}$ & $\begin{array}{l}9.0 \\
6.8\end{array}$ & $\begin{array}{l}2.93 \pm 0.30 \\
3.71 \pm 0.15\end{array}$ & $\begin{array}{l}0.40 \pm 0.08 \\
0.45 \pm 0.06\end{array}$ \\
\hline 11 & $\mathrm{~N}$ alone & 4 & 48 & 4.2 & 2.2 & $4.16 \pm 0.16$ & $0.45 \pm 0.06$ \\
\hline \multicolumn{2}{|c|}{ Control } & 29 & 370 & 2.7 & 0.58 & $3.84 \pm 0.47$ & $0.53 \pm 0.05$ \\
\hline
\end{tabular}

nervous system defects, whereas ATDA treatment during later organogenesis (days 11-14) resulted mostly in skeletal malformations. The reason for the high incidence of hydrocephalus after day 14 treatment is not known.

The fact that the embryos were particularly susceptible to the lethal effects of ATDA treatment at day 5 raises the question of whether ATDA interferes with implantation. In the rat implantation begins sometime during day 5 of gestation (sperm day $=0$ ). The treatment could have killed the blastocyst outright or prevented or delayed implantation, e.g., by interfering with the shedding of the zona pellucida or by altering the adhesive and/ or invasive properties of the trophoblast cells. An effect on the uterus may change the receptivity of the endometrium for the blastocyst. Studies of implantation in the rat (Christie, '66, '67), mouse (Wong and Dickson, '69), and rabbit (Hafez and White, '67) have shown alterations in nicotinamide adenine dinucleotide (NAD) dependent enzymes related to carbohydrate, lipid, and protein metabolism in both the uterine endometrium and blastocyst at the time of implantation. ATDA is considered to be a nicotinamide antagonist and may act by interfering with either the synthesis of NAD or its utilization as a coenzyme. ATDA could thus alter the metabolism in the blastocyst and/or uterus, upsetting the delicate balance between the two systems, and result in failure of nidation.

A second period of susceptibility to the embryolethal action of ATDA was at days 9-10. The basis for the susceptibility at this period is not known, but it may be related to the establishment of the circulatory system at this time. The cardiac primordia become recognizable at day 10 and during the next 48 hours the bilateral primordia of the heart fuse and begin to beat, and the heart begins to undergo its complex series of convolutions. The first three pairs of aortic arches are established during this time and the major blood channels of the early embryo are formed. At this early stage in development interference with the establishment of the circulatory system would more directly lead to immediate embryonic death than would interference with other developing systems.

There is ample evidence that nicotinamide can protect chick embryos against the teratogenic effects of various compounds, e.g., insulin (Landauer, '48), certain sulphonamides (Landauer and $\mathrm{Wa}$ kasugi, '68), and 3-acetylpyridine and 6-aminonicotinamide (Landauer, '57; Caplan, '72a): the last two are nicotinamide analogues. Caplan (72a) proposed that in the chick embryo nicotinamide acts to protect against nicotinamide-sensitive ter- 
atogens by maintaining the NAD pool at a level sufficient for energy metabolism required for growth and differentiation. In mammals complete protection was noted against the teratogenic effects of 6-aminonicotinamide in mice (Pinsky and Fraser, '60), rats (Chamberlain and Nelson, '63), and rabbits (Grote et al., '71). The results of the present investigation support the conclusion that supplemental nicotinamide can protect against the detrimental prenatal effects of nicotinamide antagonists in mammals.

Landauer and coworkers found that many chick teratogens apparently act by interfering with NAD functions, and that this interference can be completely overcome by providing appropriate amounts of nicotinamide at the appropriate time during embryogenesis (see Landauer and Wakasugi, '68, for recent summation). They suggested that nicotinamide probably acts by competing with the antagonist for sites of attachment and proposed that nicotinamide-sensitive teratogens exert their effects by depriving specific embryonic sites of energy required for normal functions. Caplan ('70, '72b) recently showed, through the use of 3-acetylpyridine, a nicotinamide-sensitive teratogen, that nicotinamide plays a vital role in the differentiation of chick limb-bud mesoderm into chondrogenic and myogenic elements. He suggested that tissue concentrations of essential compounds such as nicotinamide may very well control the route of cellular differentiation of undifferentiated cells.

The first morphological evidence of ATDA action is seen in the developing neural tube and mesenchyme (Beaudoin, '71). Six hours after treatment at day 11 there were no observable effects, but by 24 hours there were signs of extensive cell necrosis in the aforementioned tissues. The greatest number of dead and dying cells were present in the caudal region of the embryo (taillessness is a predominant defect following ATDA treatment at day 11). Necrosis was evident until 72 hours after treatment at which time repair and tissue reorganization became evident. It was postulated that the extent of cell death influenced the quantity, and perhaps the quality, of the subsequent repair and reorganization. Scott et al.
(72) reported similar findings following ATDA treatment at day 12 . They noted the first evidence of cell necrosis in the forelimbs at 11 hours after treatment, which reached a peak at 23 hours followed by reduction deformities of the digits at term. They proposed that the observed limb malformations were the result of the extensive cell death caused by the ATDA.

It is apparent that nicotinamide-sensitive teratogens can be useful tools in the study of abnormal development. Runner (59) stated that to be most informative an experimental procedure for inducing anomalies should "(1) be effective in an acute experiment; (2) be reversible by an antidote (i.e., protection from the insult) and (3) permit inference about the chemical mode of action of the teratogenic agent." The thiadiazole-nicotinamide system appears to fulfill these requirements.

\section{LITERATURE CITED}

Beaudoin, A. R. 1971 Teratogen-induced myelodysplasia and taillessness in the Wistar albino rat. Teratology, 4: 228-229 (abst.).

- 1972 Teratogenic action of 2-amino1,3,4-thiadiazole in rats. Teratology, 5: 250 (abst.).

Caplan, A. I. 1970 Effects of the nicotinamidesensitive teratogen 3-acetylpyridine on chick limb cells in culture. Exp., Cell Res., 62: 341355 .

1972a Comparison of the capacity of nicotinamide and nicotinic acid to relieve the effects of muscle and cartilage teratogens in developing chick embryos. Dev. Biol., 28: 344351 .

1972b The effects of the nicotinamidesensitive teratogen 3-acetylpyridine on chick limb mesodermal cells in culture: biochemical parameters. J. Exp. Zool., 180: 351-362.

Chamberlain, J. G., and M. M. Nelson 1963 Congenital abnormalities in the rat resulting from single injections of 6-aminonicotinamide during pregnancy. J. Exp. Zool., 153: 285-300.

Christie, G. A. 1966 Implantation of the rat embryo: glycogen and alkaline phosphatases. J. Reprod. Fert., 12: 279-294.

1967 Implantation of the rat embryo: further histochemical observations on carbohydrate, RNA and lipid metabolic pathways. J. Reprod. Fert., 13: 281-296.

Grote, W., U. Claussen and D. Heinz 1971 Verursachung und Verhütung von Entwicklungsstörungen beim Kaninchen durch Verabreichung von 6-Amino-nikotinsäureamid und Nikotinsäureamid. Arzneimittelforschung, 21: 825-828.

Hafez, E. S. E., and I. G. White 1967 Endometrial and embryonic enzymes in relation to implantation of the rabbit blastocyst. Anat. Rec., 153: 273-280.

Humphreys, S. R., J. M. Venditti, C. J. Ciotti, 
I. Kline, A. Goldin and N. O. Kaplan 1962 Toxicity and antileukemic effectiveness of pyridine derivatives and 1,3,4-thiadiazole derivatives in mice. Relationship to nicotinamide antagonism. Cancer Res., 22: 483-550.

Krakoff, I. H., and M. E. Balis 1959 Studies of the uricogenic effect of 2 -substituted thiadiazoles in man. J. Clin. Inv., 38: 907-915.

Krakoff, I. H., and G. B. Magill 1956 Effects of 2-ethylamino-1,3,4-thiadiazole $\mathrm{HCl}$ on uric acid production in man. Proc. Soc. Exp. Biol. Med., $91: 470-472$

Landauer, W. 1948 The effect of nicotinamide and $\alpha$ ketoglutaric acid on the teratogenic action of insulin. J. Exp. Zool., 109: 283-290.

1957 Niacin antagonist and chick development. J. Exp. Zool., 136: 509-530.

Landauer, W., and N. Wakasugi 1968 Teratological studies with sulphonamides and their implications. J. Embryol. Exp. Morph., 20: 261284.

Murphy, M. L., C. P. Dagg and D. A. Karnofsky 1957 Comparison of teratogenic chemicals in the rat and chick embryos. Pediatrics, 19: 701714.

Oleson, J. J., A. Sloboda, W. P. Troy, S. L. Halliday, M. J. Landes, R. B. Angier, J. Semb, K. Cyr and J. H. Williams 1955 The carcinostatic activity of some 2-amino-1,3,4-thiadiazoles. J. Am. Chem. Soc., 77: 6713-6714.

Pinsky, L., and F. C. Fraser 1960 Congenital malformation after a two-hour inactivation of nicotinamide in pregnant mice. Br. Med. J., 2: 195-197.

Runner, M. N. 1959 Inheritance of susceptibility to congenital deformity. Metabolic clues provided by experiments with teratogenic agents. Pediatrics, 23: 245-251.

Scott, W. J., J. G. Wilson and E. J. Ritter 1972 The teratogenic, biochemical and histological effects of aminothiadiazole and their reversibility by nicotinamide. Teratology, 5: 266 (abst.).

Shapiro, D. M., M. E. Shils, R. A. Fugmann and I. M. Friedland 1957 Quantitative biochemical differences between tumor and host as a basis for cancer chemotherapy. IV. Niacin and 2-ethylamino-1,3,4-thiadiazole. Cancer Res., 17: 29-33.

Wong, Y. C., and A. D. Dickson 1969 A histochemical study of ovo-implantation in the mouse. J. Anat., 105: 547-555.

Woo, D. C., and R. M. Hoar 1972 "Apparent hydronephrosis" as a normal aspect of renal development in late gestation of rats: the effect of methyl salicylate. Teratology, 6: 191-200. 